\title{
Steady State and Transient Analysis of FSIG and DFIG Integration to Grid for Different Penetration Levels using VSC-HVDC
}

\author{
Noorcheshma P, Sreedevi J, Meera KS, V. Sivaprasad
}

\begin{abstract}
Among all the Renewable Energy Sources Wind energy is the fastest growing energy source over the last decade mainly due to crucial developments of technology in wind energy. Nowadays, the penetration of wind energy is increasing in many countries in the world including India. The power system stability with large penetration of wind power is a concern for many electrical utilities. The common technical issues with increased penetration of wind energy are voltage and reactive power control, frequency control and Low Voltage Ride Through (LVRT) capability. The VSC-HVDC system with its benefit of independent control of active and reactive power promises to enhance the system stability at high penetration levels. The maximum wind penetration levels in to the grid is analysed for Fixed Speed Induction Generator (FSIG) \& Doubly Fed Induction Generator (DFIG). The penetration levels are further enhanced by considering the evacuation of wind power with VSC-HVDC system without losing system stability. Different controllers for VSC-HVDC system are used to improve the stability and LVRT capability. Standard Benchmark System is considered, and the simulations are performed by using power system simulation software SIMPOW. Results shows that wind power evacuated through VSC-HVDC system has better stability and LVRT Capability compared to AC system at high wind penetration levels.
\end{abstract}

Keywords : Wind Farm, Wind Penetration, Fixed Speed Induction Generator, Doubly Fed Induction Generator, Low Voltage Ride Through, VSC-HVDC.

\section{INTRODUCTION}

At present fundamental importance of renewable energy in power system is increasing day by day mainly Wind Energy. Integration of such huge amount of wind energy in to the existing AC power grid is a major challenge. The unprecedented increase of wind energy in power systems has resulted in stricter grid code requirements that windfarm operators to be followed, most of such requirements fall under Reactive power capability issue to Fault ride through capability [1], [2]. To reduce such problems, High Voltage Direct Current (HVDC) system is the ideal solution to transmit power to long distances and integrate renewable energy sources to the grid, specifically with VSC-HVDC transmission system [3],[4]. VSC transmission has many advantages such as reactive power control is possible

Revised Manuscript Received on March 5, 2020.

Noorcheshma P*, Senior Research Fellow, Power Systems Division, Central Power Research Institute, Bengaluru, India. E-mail: Noorcheshma.p@gmail.com

Sreedevi J, Joint Director, Power Systems Division, Central Power Research Institute, Bengaluru, India. E-mail: sreedevi@cpri.in

Meera K S, Additional Director, Power Systems Division, Central Power Research Institute, Bengaluru, India. E-mail: meera@cpri.in

Dr.V.SivaPrasad, Professor, Department of EEE, SIT, Tumakuru, India. E-mail: vspsit@rediffmail.com

independent of the transmitted real power and ultimately improves stability of the grid. Ability of VSC to decouple the rectifier and inverter system, allowing both sides operating individually enables the ideal solution for integration issue of renewable energy [5]-[7]. Thus, VSC-HVDC facilitates in meeting the grid code compliance for renewable energy resources.

Wind farms (WF) can be connected in three ways to main power system; AC connection, Conventional HVDC connection and VSC-HVDC connection [8]. Generally, AC transmission is used to transfer offshore wind power to grid when distance to the shore is less. As windfarm capacity increases and distances to shore is more, grid integration of large offshore windfarms using long AC submarine cables have high capacitive charging currents, which requires more reactive power compensation and reduces the current carrying capability due to increased power losses. A grid fault may substantially affect seamless operation of wind farm because of its poor fault ride through capability, which leads to voltage collapse in the absence of reactive power support [9]. Thus, HVDC technologies based on voltage source converters have a significant advantage over an AC connection for grid integration of a large offshore wind farms. Main features of VSC-HVDC system in wind power evacuation are

1) Capability to deliver bulk amount of power over very long distances with trivial losses.

2) The switching device (STATCOM) in Converter stations enables reactive power compensation to the grid during steady state and transient condition.

3) It enhances fault ride through capability of the wind farms such that fault in the ac grid will not impact the wind farm's ac voltage due to sending and receiving end converters are decoupled by the asynchronous connection [10]- [12].

4) VSC-HVDC system not only compensates the fluctuations in wind power and also aids in stabilizing irregular power flows those generated by wind farms.

5) It also supports weak grid with black start capability i.e., grid restoration is possible with VSC-HVDC system when large area of the power system shut down. Hence VSC-HVDC system is a feasible solution for integration of large-scale renewable energy sources to the grid. [13], [14].

As grid integration of wind energy increasing continuously, power system dynamics and stability needs to be studied thoroughly. The authors in [15]-[17] given emphasis on the characteristics of the power system and notably on the various impacts of high penetration levels of wind power, such as voltage stability, frequency stability, power oscillations and transient stability. 
Studies were carried out on transient stability of power system with high wind penetration, but considered either FSIG or DFIG wind machines with AC system evacuating power to grid [18]. DFIG based wind farms showed significant improvement in system stability due to their reduced reactive power consumption [19], [20]. DFIG based wind farms have improved stability during low penetration levels of wind but stability of the system can be significantly reduced by $50 \%$ during high penetration levels of wind due to the high reactive power consumption of wind generators during fault [21]. Hence the VSC-HVDC is considered to evacuate the power at high penetration levels.

With the capacity of wind generators in power system rapidly increasing, the analysis of integration of different wind generators to the grid has become necessary. The main objective of this paper is to quantify the maximum wind penetration levels with FSIG \& DFIG in to the grid without losing system stability. Wind penetration levels are further increased beyond the stability limits of AC system by using VSC-HVDC system with suitable controllers. Constant active and reactive power controllers are used at rectifier side to maintain constant wind power evacuation. Constant AC voltage and DC voltage controllers are used at inverter side to maintain voltage at AC grid. These VSC controllers gives best results in improving the system stability with high wind penetration levels. In an integrated $\mathrm{AC} \& \mathrm{DC}$ system considered, the LVRT capability of the wind machines at rectifier side of the VSC-HVDC system is also analyzed for different cases.

The remaining part of the paper is arranged accordingly. Section II of the paper gives System configuration considered. Section III describes the Modelling of FSIG, DFIG \& VSC-HVDC and its controls. Section IV presents the Simulation studies for different penetration levels of FSIG \& DFIG based wind farm by considering without \& with VSC-HVDC. Fault cases and LVRT capability for different cases are also studied. Conclusion in Section $\mathrm{V}$ completes the paper with effectiveness of VSC- HVDC for better transient stability and LVRT capability.

\section{SYSTEM DESCRIPTION}

The Kundur's Two-Area System [22] is considered in this paper for the simulation studies. Figure 1 shows the single line diagram of the system. It consists of eleven buses and the two areas are linked by a weak tie among Bus 7 and Bus 9. Area 1 represented as left half of the system and Area 2 as right half of the system. Loads and Shunt Capacitors are present in the system at Bus 7 and Bus 9. Each area has two generators, each with a capacity of 700MW.

For this system, two types of wind turbine generators, FSIG \& DFIG are connected at Bus 5 to analyse the LVRT capability. An additional line (Bus 7 to Bus T) is considered to analyze LVRT capability at rectifier side of the DC system due to presence of VSC-HVDC link. The power generated from wind turbine generator and conventional generators (G1 $\&$ G2) is evacuated through the tie lines between Bus 7 and Bus 9. The LVRT capability is further analysed by connecting the VSC-HVDC line of 400MW between Bus 7 and Bus 9 by replacing the Double Circuit (D/C) tie lines. One of the main reasons for replacing AC circuit with DC circuit is the maximum penetration of wind can be possible with VSC-HVDC. The studies are carried out using SIMPOW software [23].

\section{MODELLING DETAILS OF SYSTEM IN SIMPOW}

Synchronous machines G1, G2, G3 and G4 are modelled in detail by d-axis consists of one field winding and one damper winding while q-axis consists of two damper windings. The excitation system is modelled as IEEE-Type1.

FSIG is modelled as an asynchronous machine, transient model without saturation whereas the variable speed WTG is modelled as DFIG. The detailed and complete model of DFIG wind turbine and its controllers such are speed control, Pitch control, Crow-bar control (protection) \& AC bus voltage control are explained in [24].

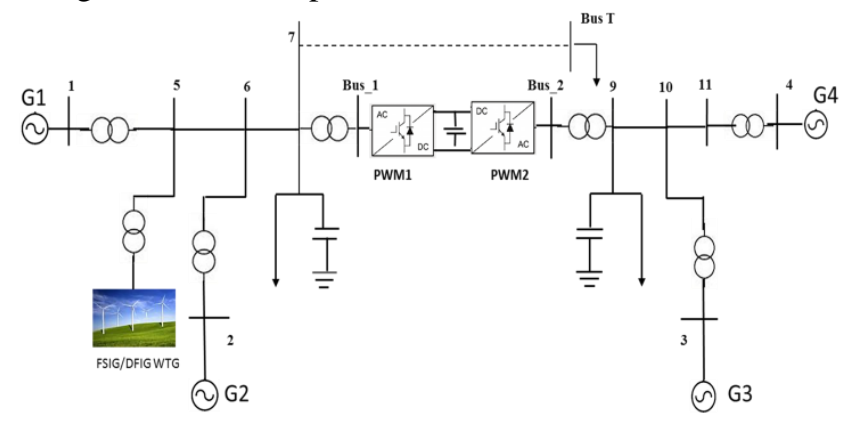

Fig. 1. The System considered for the study

It is possible to produce any desired wave form by selecting the switching instant of the valves in the VSCs, which can be controlled by a control signal. AC voltage with any phase angle or voltage amplitude can be recreated using PWM technology, which is appropriate for high switching frequencies. Active and reactive power can therefore be independently controlled using by VSC-HVDC with PWM technique. VSC-HVDC transmission system model comprises of converter transformers, PWM converters and an intermediate dc system as shown in Figure 2. Both Bus $7 \&$ Bus 9 have an $\mathrm{AC}$ filter, series reactor and converter connected to them. The different control modes that can be modelled at rectifier side are Active power control mode and Reactive power control mode, whereas at inverter side are $\mathrm{DC}$ voltage control mode and AC voltage control mode. The converter in active power control mode controls the transfer of real power into or out of the DC system based on an active power order and the converter in DC voltage control mode controls the active power into or out of the AC grid by keeping the DC system voltage at constant value. The PWM converter which is operating in the strongest network is generally in DC voltage control mode and other PWM converter can control the reactive power or the AC voltage at the grid side of the converter transformers. The VSC-HVDC model interacts with the AC networks through the injected currents and the node voltages of the networks are determined by the Kirchhoff's law [23].

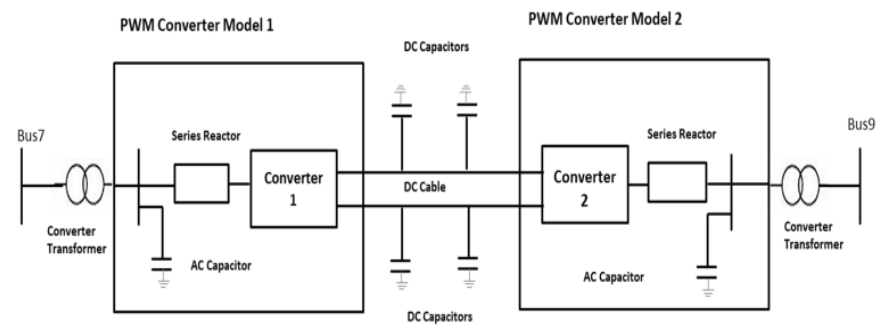

Fig. 2. VSC-HVDC Model 


\section{SIMULATION STUDIES \& RESULTS}

\section{A. Load Flow Studies}

- Case a-Kundur Two Area System without wind generation: Load Flow studies were initially carried out without wind generation. The total generation of the system considered in this case is $2819 \mathrm{MW}$. Generators G1, G2 \& G4 are delivering a power of 700MW and the generator G3 is delivering power of $718.9 \mathrm{MW}$ which is considered as slack generation bus. This is considered as base case and different types of wind generations are added to this case by reducing the conventional generation in the cases discussed below.

- Case b- Kundur Two Area System with FSIG wind Generation: Initially Fixed Speed Induction Generators are considered by reducing conventional generation of G1 \& G2 without changing the load in the system. $1100 \mathrm{MW}$ wind farm consisting of $7 \times 157.5 \mathrm{MW}$ lumped wind generators, each with 105 wind turbines of $1.5 \mathrm{MW}$ rating has been connected to the test system (Figure 1) at Bus 5 through $11 / 230 \mathrm{kV}$ transformer. The maximum wind generation that can be added without altering the static network data is found to be $1100 \mathrm{MW}$ which is $39 \%$ of wind penetration into the system. The ratio of wind generation to the total generation of the system is called Wind penetration. A reactive power compensation of $40 \%$ of the machine rating is added at wind generator terminal as FSIGs can lead to voltage instability of the grid without compensation.

- Case c-Kundur Two Area System with FSIG wind generation integrated through VSC-HVDC:The VSC-HVDC controls considered are active power control mode and reactive power control mode at rectifier side (BUS 7) to maintain constant active power transmission; DC voltage control mode and AC voltage control mode at Inverter side (BUS 9) to maintain AC voltage at inverter terminals.

When FSIG based wind farm is integrated to grid through VSC-HVDC system, the penetration of wind is increased from $39 \%$ to $50 \%$. A wind generation of $1400 \mathrm{MW}$ was possible in contrast to the $1100 \mathrm{MW}$ in previous case.

- Case d-Kundur Two Area System with DFIG wind generation: Similar to Case $b$, the simulations are carried out by considering DFIG based wind farm at Bus 5 . Wind farm of $7 \times 171 \mathrm{MW}$ lumped wind generators, each with 114 wind turbines of $1.5 \mathrm{MW}$ rating were connected to the test system at Bus 5 through $11 / 230 \mathrm{kV}$ transformer. The maximum penetration of wind

observed to be $42.6 \%$. Reactive power compensation is not necessary when DFIG based wind farm is integrated to the grid.

- Case e-Kundur Two Area System with DFIG wind generation integrated through VSC-HVDC: When DFIG based wind farm is integrated to grid with VSC-HVDC, the

penetration of wind is increased from $42.6 \%$ to $46.12 \%$. A wind generation of $1300 \mathrm{MW}$ was possible to integrate with grid in contrast to the $1200 \mathrm{MW}$ in previous case. The power output from different generators for all the cases above is given in Table 1 along with the feasible wind penetration levels for the study system.

\section{B. Power factor analysis at Point of Common Coupling}

The wind and solar farms must maintain a power factor of 0.95 and above at PCC for all dispatch scenarios by supplying adequate reactive compensation [25]. For the system considered, power factor variation of 0.975-0.99 is observed at PCC (Bus 5) for various wind penetration levels, as shown in Figures $3 a$ and $3 b$.

The graphs show that the reactive power compensation provided with FSIG results in better power factor at PCC with and without VSC-HVDC system and the power factor can be regulated to a constant value with the help of VSC-HVDC controls.

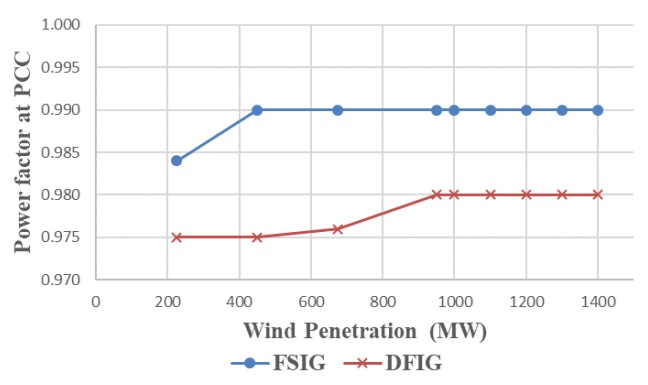

Fig.3a. Power factor at PCC for different wind penetrations without VSC-HVDC

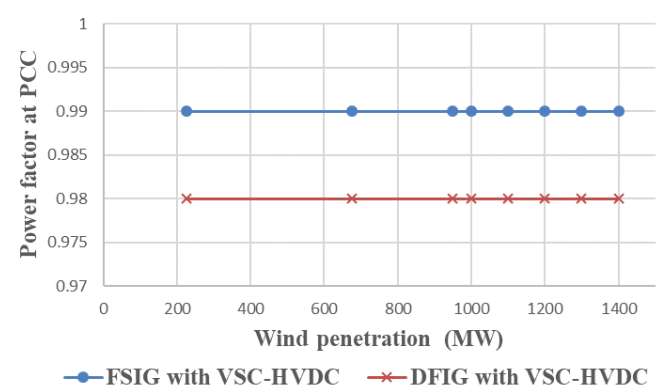

Fig.3b. Power factor at PCC for different wind penetrations with VSC-HVDC

\section{Voltage profile analysis at PCC}

With high wind penetration, the voltage stability is an important issue for wind farms integrated to AC network. As wind penetration increases, voltage at PCC reduces. Especially WFs equipped with FSIG consumes reactive power and doesn't support voltage,

Table-I: Feasible Wind Penetration Levels of FSIG \& DFIG based Wind Farm Without \& With Integration of VSC-HVDC

\begin{tabular}{|l|c|c|c|c|}
\hline \multicolumn{1}{|c|}{ Generators } & $\begin{array}{l}\text { Case a: without } \\
\text { wind Generation }\end{array}$ & Case b: with FSIG & $\begin{array}{l}\text { Case c: with FSIG } \\
\text { \& VSC -HVDC }\end{array}$ & $\begin{array}{l}\text { Case d: } \\
\text { with DFIG }\end{array}$ \\
\hline G1 P(MW) & 700 & 25 & 41 & 25 \\
\hline G2 P(MW) & 700 & 275 & 25 & 175 \\
-HVDC
\end{tabular}




\begin{tabular}{|c|c|c|c|c|c|}
\hline G3 P(MW) & 718.9 & 724.55 & 710.8 & 752.3 & 710.4 \\
\hline G4 P(MW) & 700 & 700 & 700 & 700 & 700 \\
\hline Wind $\mathrm{P}(\mathrm{MW})$ & 0 & 1100 & 1400 & 1200 & 1300 \\
\hline Wind Penetration* & $0 \%$ & $39 \%$ & $50 \%$ & $42.6 \%$ & $46.12 \%$ \\
\hline Transient Case & Stable & Stable & stable & stable & Stable \\
\hline
\end{tabular}

hence capacitor banks are widely used. Whereas DFIG WTGs provide grid voltage support due to power electronics converter between grid side and rotor side. For the system considered, the voltage profile is good at PCC when DFIG wind farms are connected to the grid with increase in penetration and is shown in Figures $4 \mathrm{a}$ and $4 \mathrm{~b}$. VSC-HVDC does not have any added advantage in maintaining the voltage profile at PCC as the Bus 5 is not a voltage-controlled bus for VSC-HVDC.

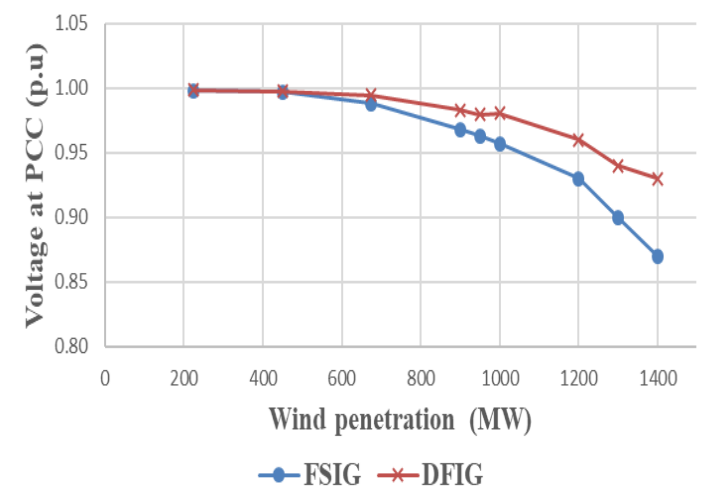

Fig. 4a. Voltage at PCC for different wind penetrations without VSC-HVDC

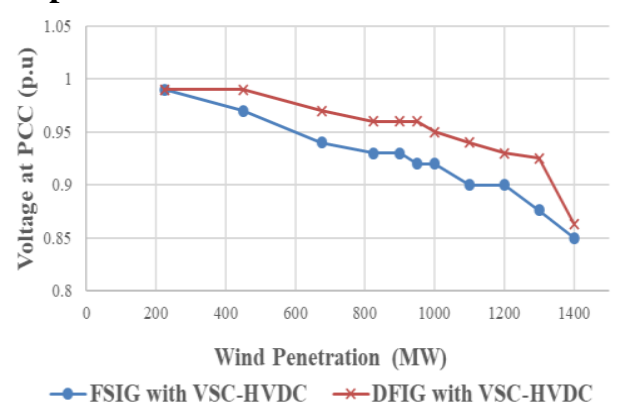

Fig. 4b. Voltages at PCC for different wind penetrations with VSC-HVDC

\section{Analysis of losses}

Real and Reactive power losses are increased as wind penetration increases. However, DFIG WTG is maintaining good voltage profile which leads to the reduction of power losses as shown in Figures $5 \mathrm{a} \& 5 \mathrm{~b}$. The reactive power losses presented in Figures $5 \mathrm{c} \& 5 \mathrm{~d}$ are high compared to active power losses.

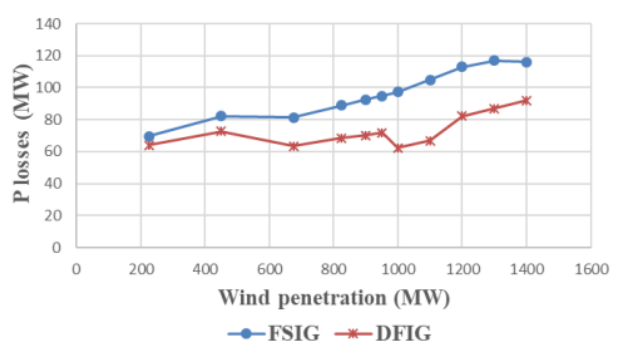

Fig. 5a. $P$ losses for different wind penetrations without VSC-HVDC

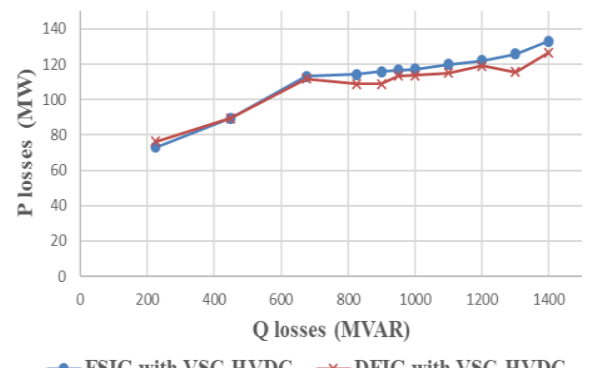

$\rightarrow$ FSIG with VSC-HVDC $\quad$ *DFIG with VSC-HVDC

Fig. 5b. P losses for different wind penetrations with VSC-HVDC

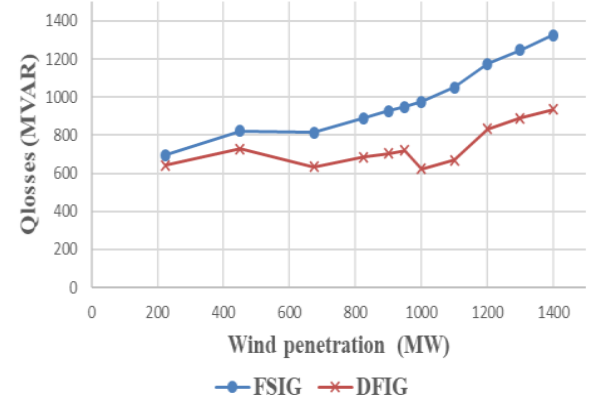

Fig. 5c. Q losses for different wind penetrations without VSC-HVDC

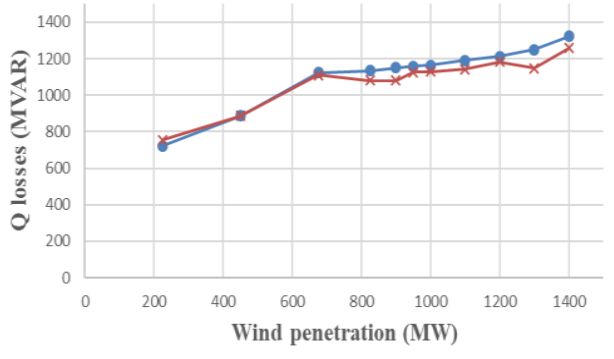

$\rightarrow$ FSIG with VSC-HVDC $\rightarrow$ *DFIG with VSC-HVDC

Fig. 5d. Q losses for different wind penetrations with VSC-HVDC

\section{E. Transient stability studies}

Stability studies for the system were carried out and the converged power flow results in section A will provide the initial system conditions. The total generation in Area 1 can be replaced with wind generation in the considered system without changing the static data of the network and converged load flow was obtained which gives the steady state penetration level. Whereas the system is transiently stable for the wind penetration levels as provided in Table 1.

Figures $6 \mathrm{a}$ and $6 \mathrm{~b}$ show the transient stability results for Case $b$, for stable and unstable penetration levels with three phase to ground fault for a fault duration of $160 \mathrm{~ms}$ at Bus 7. Similarly, graphs shown in Figures $6 \mathrm{c}$ and $6 \mathrm{~d}$ are for Case d. The stability of the system is improved with DFIG and it controls for higher penetration levels.

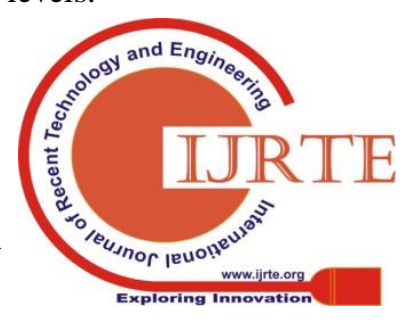




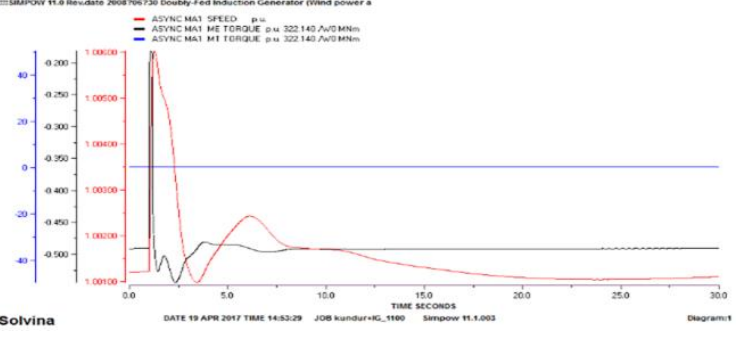

Fig. 6a. Speed, mechanical \& electrical torque of FSIG for Case $b$ - stable ( $39 \%$ penetration)

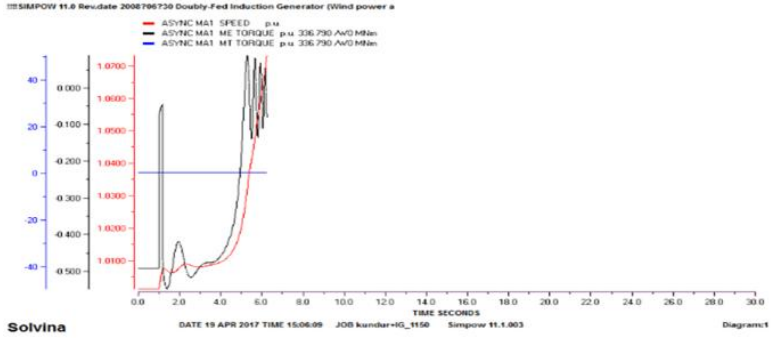

Fig. 6b. Speed, mechanical \& electrical torque of FSIG for Case b- unstable ( $40 \%$ penetration)

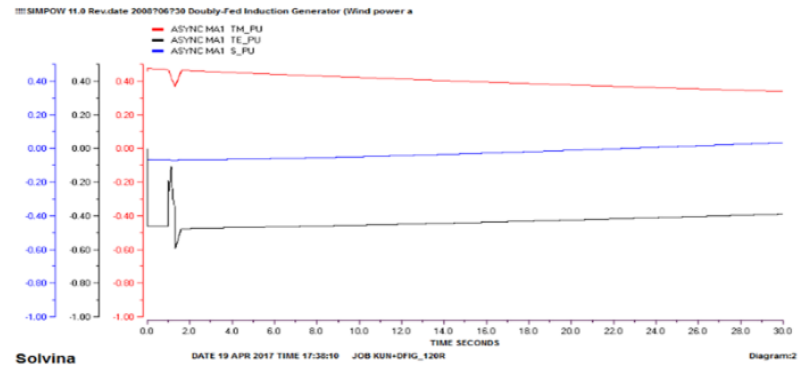

Fig. 6c. Speed, mechanical \& electrical torque of DFIG for Case d- stable (42.6\% Penetration)

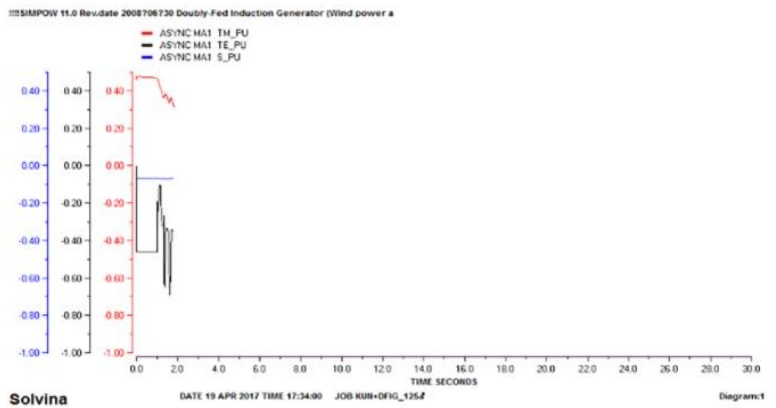

Fig. 6d. Speed, mechanical \& electrical torque of DFIG for Case $d$ - unstable ( $43 \%$ penetration)

In Case $\mathrm{c}$ the total generation of Area 1 is replaced by wind generation and the wind penetration reaches its ceiling of $50 \%$. The system is stable and wind generation is not increased further to maintain the balance of load generation in the system so there is no unstable case.The VSC-HVDC transmission provides added support to grid with its capability and independent control of active and reactive power. Stability of the system is improved with VSC-HVDC with increased penetration of wind from $39 \%$ to $50 \%$. Graphs in Figures $7 \mathrm{a}$ and $7 \mathrm{~b}$ are pertaining to this case.

In Case e, the wind penetration is increased from $42.6 \%$ to $46.12 \%$ by using VSC-HVDC. Figures $7 \mathrm{c}$ and $7 \mathrm{~d}$ show the stable and unstable graphs for Case e.

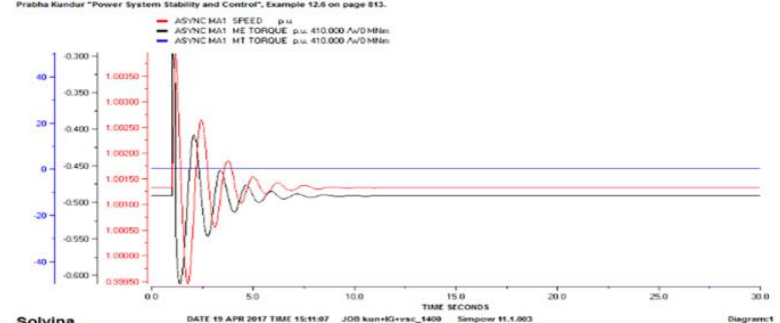

Fig. 7a. Speed, mechanical \& electrical torque of FSIG for Case c- stable (50\% penetration)

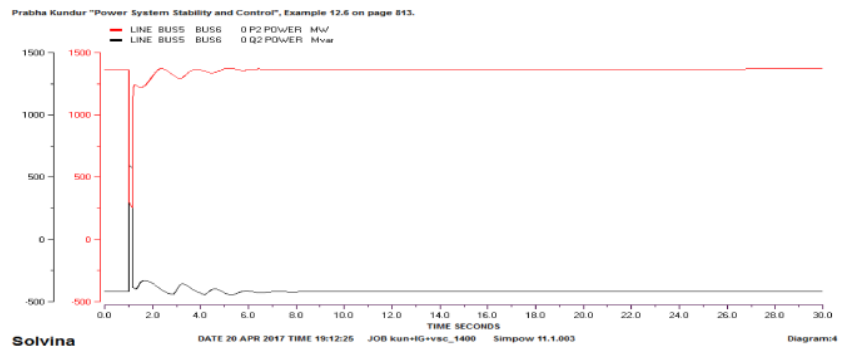

Fig. 7b. Real and Reactive power through line Bus 5 to Bus 6 for Case c-stable (50\% penetration)

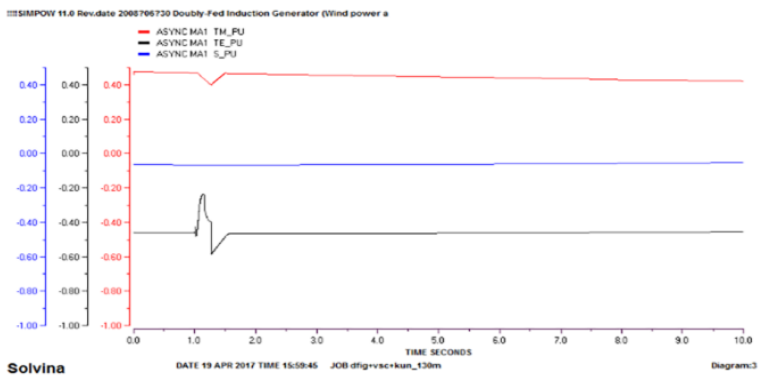

Fig. 7c. Speed, mechanical \& electrical torque of DFIG for Case e- stable

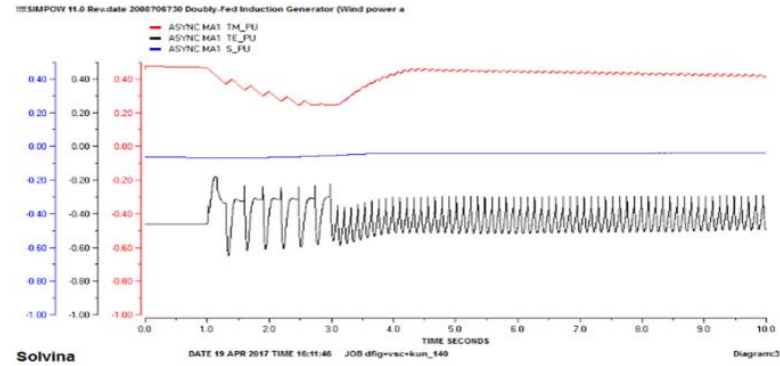

Fig. 7d. Speed, mechanical \& electrical torque of DFIG for Case e - unstable

\section{F. LVRT analysis of wind turbine}

In the past, windfarms were allowed to trip during grid disturbances and reconnected immediately after fault was cleared and voltage returned to the normal value. Today, as wind penetration increases, the wind grid code demands the windfarms should not be isolated from the grid during network disturbance to avoid large deviations in power and supply frequency. Such requirement is known as Low Voltage Ride Through capability (LVRT). Constant speed wind turbine generators do not have the ability to regulate the voltage and reactive power. Therefore, they do not have fault ride through capability unless additional voltage controlling equipment or reactive power is supplied to grid under fault conditions. 
However, Variable speed wind turbines such are DFIG \& PMSG have no reactive power constraints. Thus, these wind turbine generators have fault ride through capability with power electronics converter control [26]. Figure 8 shows the fault ride through characteristics of wind turbine generators connected to the grid. Wind farms must not to be trip when the voltage dip profile is in shaded region or else disconnected if the voltage at PCC drops below the shaded line as shown in Figure 8. The parameters Vpf, Vf and T vary for each country based on their grid code.

The LVRT capability is checked for the system considered by creating a fault at Bus T, which is $40 \mathrm{~km}$ away from Bus 7 to simulate the far end grid fault for all cases in Section A. At 1.0 seconds three phase to ground fault is created at Bus T for a duration of $160 \mathrm{~ms}$. Bus voltage at PCC (Bus 5), Bus T and speed of the wind generators is plotted for all cases in Section $\mathrm{A}$ and are given in Figure 9. It is observed from the speed graphs that for a dip in voltage of 8 cycles, there is no disconnection of wind generators from the system. The dip in voltage for case b, c, $\mathrm{d}$ and e is $10 \%, 6.25 \%, 46 \%$ and $11.22 \%$ respectively. It is observed from results that all cases are meeting LVRT capability as per Grid code 2010. However, the results of FSIG with VSC-HVDC have better LVRT capability.

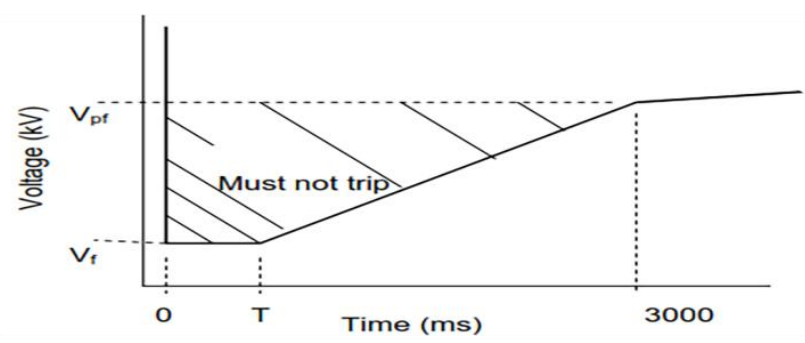

Fig. 8. Fault ride through characteristics

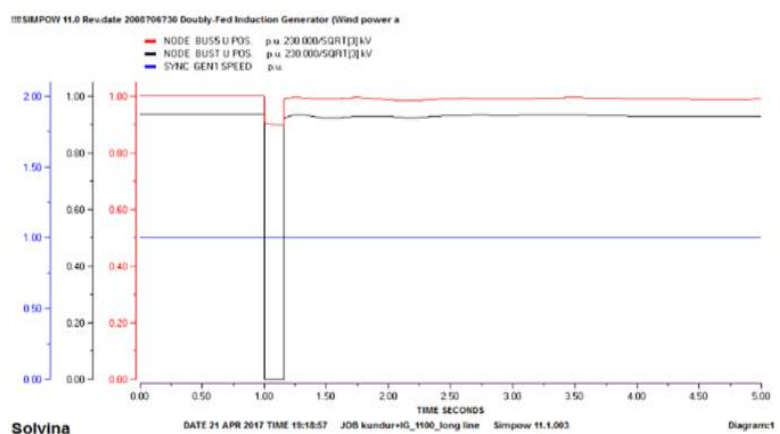

Fig. 9a. Voltage at PCC, Faulted Bus (Bus T) and Speed of wind machine - Case $b$

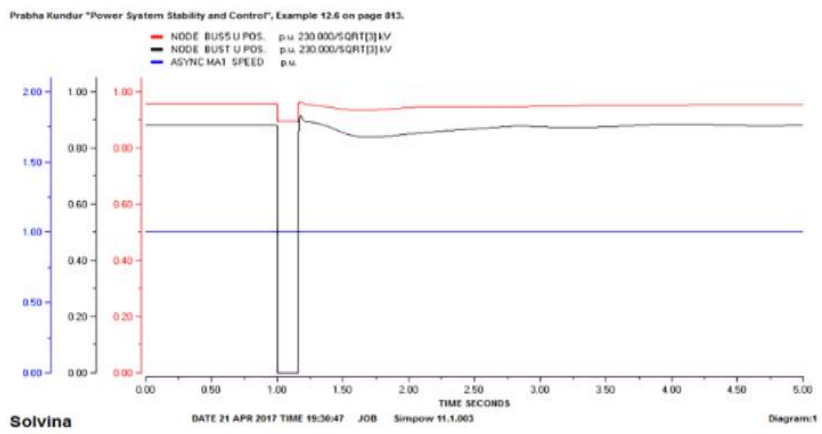

Fig. 9b. Voltage at PCC, Faulted Bus (Bus T) and Speed of wind machine - Case $\mathrm{c}$

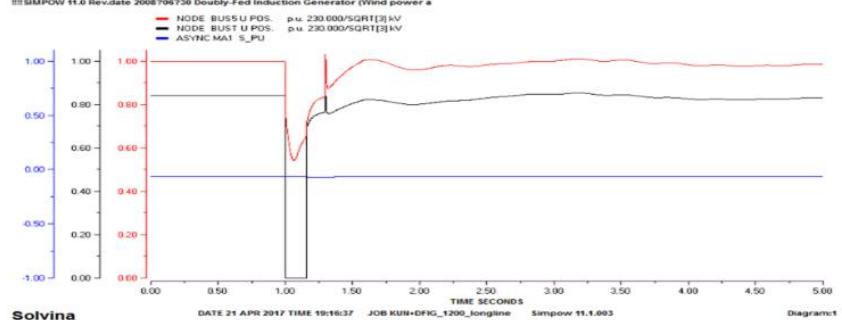

Fig. 9c. Voltage at PCC, Faulted Bus (Bus T) and Speed of wind machine - Case $d$

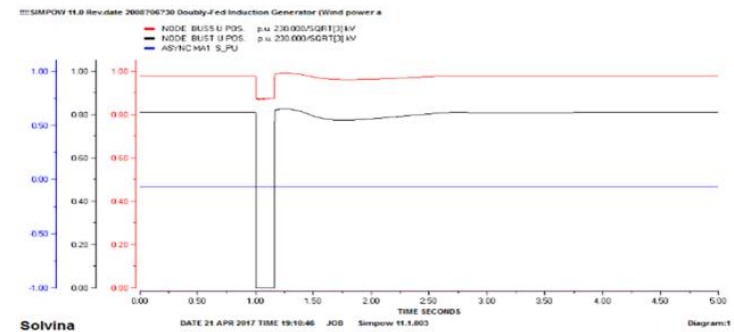

Fig. 9d. Voltage at PCC, Faulted Bus (Bus T) and Speed of wind machine - Case $e$

\section{CONCLUSION}

This paper deals with two ways of integrating wind farms to grid through AC \& VSC-HVDC connection system. The power factor and voltage profile analysis along with transient stability and LVRT capability of renewable energy integration system with increased wind penetration is studied. None of the transmission lines and transformers got overloaded with increased wind penetration as the load generation balance is maintained. From the studies it is observed that maximum wind penetration and better LVRT capability is with FSIG WTG integrated through VSC-HVDC. From the voltage profile analysis, it has been observed that voltage is reducing at increased wind penetration levels and the real power losses are increased. DFIG WTG has AC voltage controller to maintain better voltage profile and thereby reduced real power losses. As the VSC-HVDC system can independently control active and reactive power, the cases with VSC-HVDC system show better results. The DC capacitor present in VSC-HVDC charges and discharges and provides necessary voltage support required for dynamic variations in voltage.

\section{ACKNOWLEDGMENT}

The authors wish to thank the authorities of CPRI for permitting to publish this paper.

\section{REFERENCES}

1. Tsili, M., Papathanassiou, S.: 'A review of grid code technical requirements for wind farms', IET Renew. Power Gener. 2009, 3, 308-332.

2. Indian Electricity Grid code by Central Electricity Regulatory commission, April 2010.

3. Hore, K., Kumar, A., Ujjwal, L.: 'Challenges in Renewable Energy Resources and Role of VSC-HVDC Technology in Integration to Grid', CIGRE SC B4 International Colloquium on HVDC and STATCOM, HVDC And Power Electronics International Colloquium, 25-26 September 2015, Agra, India.

4. Shrivastava,T., Shandilya, A.M., Gupta, SC.: 'Overview strategy of wind farm in VSC-HVDC power transmission' Power India International Conference (PIICON), 2016 IEEE 7th, 25-27 Nov. 2016 
5. Nikolas Flourentzou, Vassilios Agelidis, G.: 'VSC-Based HVDC Power Transmission Systems: An Overview', IEEE Trans. Power Electronics, vol. 24, no.3, pp.592-602, March2009.

6. Long, W., Nilsson, S.: 'HVDC transmission: Yesterday and today', IEEE Power Energy Mag., vol. 5, no. 2, pp. 22-31, Mar.-Apr. 2007.

7. Bahrman, M.P., Johnson, B.K.: 'The ABCs of HVDC transmission technologies', IEEE Power Energy Mag., vol. 5, no. 2, pp. 32-44, Mar.-Apr. 2007.

8. Jian Liu, Liang, H., Wei Li.: 'Research on Low Voltage Ride Through capability of wind farms grid integration using VSC-HVDC', IEEE PES Innovative Smart Grid Technologies, Tianjin, 2012, pp. 1-6.

9. Reidy, A., Watson, R.: 'Comparison of VSC based HVDC and HVAC interconnections to a large offshore wind farm', in Proc. IEEE Power Eng. Soc. Gen. Meeting, 2005, vol. 1, pp. 1-8.

10. Chaudhary, S.K., Teodorescu, R., odriguez, P.: 'Wind farm grid integration using VSC based HVDC transmission-An overview', in Proc. IEEE Energy 2030 Conf., 2008, pp. 1-7.

11. Jovcic, D. Strachan, N.: 'Offshore wind farm with centralised power conversion and DC interconnection', IET Gener. Transmiss. Distrib., vol. 3, pp. 586-595, 2009.

12. Xu, L., Yao, L.Z., Sasse, C.: 'Grid integration of large DFIG-based wind farms using VSC transmission', IEEE Trans. Power Syst., vol. 22, no. 3, pp. 976-984, Aug. 2007

13. Wang, X., Wei, X., Ning, L.: 'Integration Techniques and Transmission Schemes for Off-shore Wind Farms', Proceedings of the CSEE, 2014, 34(31): 5459-5466.

14. 'Grid integration of large-capacity Renewable Energy sources and use of large-capacity Electrical Energy Storage', http://www.iec.ch/whitepaper/pdf/iecWP-gridintegrationlargecapacityLR-en.pdf

15. Ahmed El-Klhy, Reza Iravani: 'A Review of the Impacts of Multiple Wind Power Plants on Large Power Systems Dynamics', IEEE Electrical Power \& Energy Conference (EPEC), 2013

16. Tamimi, Pahwa, Starrett.: 'Maximizing wind penetration using voltage stability based methods for sizing and locating new wind farms in power system', Power and Energy Society General Meeting, 2010 IEEE, vol., no., pp.1-7, 25-29 July 2010

17. Vittal, O., Malley, M., Keane, A.: 'A Steady-State Voltage Stability Analysis of Power Systems with High Penetrations of Wind', IEEE Transactions on Power System, vol.25, no.1, pp.433-442, Feb. 2010

18. De Almeida, R.G., Lopes, J.A.P.: 'Participation of Doubly Fed Induction Wind Generators in System Frequency Regulation', Power Systems, IEEE Transactions on, vol.22, no.3, pp.944-950, Aug. 2007

19. Vittal, E., O'Malley, M., Keane, A.: 'Rotor Angle Stability with High Penetrations of Wind Generation,” Power Systems', IEEE Transactions, vol.27, no.1, pp.353-362, Feb. 2012

20. Knuppel, T., Nielsen, T., Jensen, J.N.: 'Small-signal stability of wind power system with full-load converter interfaced wind turbines', Renewable Power Generation, IET, vol.6, no.2, pp.79-91, March 2012.

21. Lasantha Meegahapola, Damian Flynn, Tim Littler.: 'Transient Stability Analysis of a Power System with High Wind Penetration', Universities Power Engineering Conference, UPEC 2008. 43rd International PP 1-6.

22. Kundur, P.: 'Power System Stability and Control', McGraw-Hill, Inc. 1994.

23. STRI AB, SIMPOW User Manual 11.0, Release 11, Sweden, 2010.

24. Noorcheshma, P., Sreedevi, J., Meera, K.S.: 'LVRT Capability of DFIG Wind Turbines with AC Voltage and Crowbar Control', International conference on standards for smart Grid Eco System, March 2014 PP. No $162-166$.

25. Ackermann, T.: 'Wind Power in Power Systems', 2nd Edition, John Wiley \& Sons, 2012

26. Sreedevi, J., Meera, K.S., Noorcheshma, P.: 'Grid stability with large wind power integration - a case study', 2016 IEEE Region 10 Conference (TENCON), Singapore, 2016, pp. 571-575.

\section{AUTHORS PROFILE}

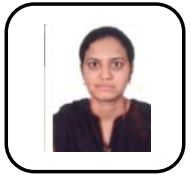

Noorcheshma $\mathbf{P}$, received B.Tech degree in Electrical and Electronics Engineering and M.Tech degree in Electrical Power Systems from Jawaharlal Nehru Technological University, Andra Pradesh, India Currently she is pursuing Ph.D from Visvesvaraya Technological University, Belgaum. Now she is working as a Senior Research Fellow at Central Power Research Institute, Bangalore. Her research interests are in the areas of Grid Integration of Renewable Energy Sources, HVDC and FACTS.

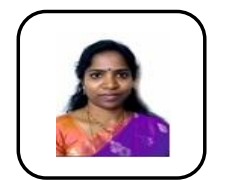

Sreedevi J completed graduation in Electricals \& Electronics Engineering from Sri Venkateswara University, Tirupati, India in 1991 and post-graduation in
System Science and Automation from IISc Bengaluru in 1994. She is presently working as a Joint Director in Power Systems Division at CPRI, Bengaluru, India. She has rendered consultancy services for various utilities and industries in areas of Power system modelling and simulation. Her research interests include real time digital simulation studies of FACTS and HVDC controllers. She is also a member of IEEE.

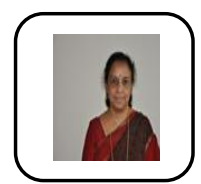

Meera K S been working in CPRI for the last 30 years, and is presently an Additional Director in the Power Systems Division. She is having expertise in the areas of modeling and simulation of power systems for transmission planning studies, System operation and control, simulation using Real Time Digital Simulator (RTDS), Dynamic testing for Protection Systems, Insulation coordination and Grid integration of Renewables. Her research areas of interest are FACTS Devices for Power Systems and Grid integration of Renewables. She has handled a large number of consultancy projects for utilities in India and abroad. She has a large number of technical publications in National and International journals in the areas of power system operation and control. She is an IEEE member and also the recipient of best research lady scientist award of CPRI for the year 2011.

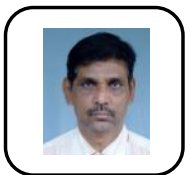

Dr. V. Siva Prasad, received Bachelors and Masters degree from JNTU College of Engineering, Anantapur, Andra Pradesh. Ph.D degree from Visvesvaraya Technological University, Belgaum. Now he is working as a Professor in SIT college, Tumkur. He has 39 years of experience in teaching. His research interests are in the areas of Voltage Stability Analysis in Power systems, Power System Operation and Control. 